\title{
Safety Issues Regarding Motorized Shopping Carts
}

\author{
Oren Masory, Ph.D. \\ Florida Atlantic University, USA, masoryo@fau.edu
}

\begin{abstract}
As the elderly population grows, the need for personal mobility devices such scooter and wheelchairs increases too. Most of these devices are used in uncrowded environment except Motorized Shopping Carts (MSCs). MSCs are operated by elderly or by people with disabilities in very confined and in times very crowded environment. In a first glance, it appears that there are no safety issues in operating MSCs due to their misleading low "walking" speed. On the contrary, there are quite a few safety issues related to MSCs operation in supermarkets, department stores and other retail facilities. This paper attempts to present some of the safety concerns which include high accelerations and jerks, Impact forces with by standers, manoeuvrability and others.
\end{abstract}

Keywords—Motorized Shopping Carts, Safety.

\section{INTRODUCTION}

There are 38441 supermarkets in the U.S. besides malls, pharmacies etc. [1]. Thus, the number of Motorized Shopping Carts (MSCs) in the U.S. can be estimated, with high probability, to be above 50,000. It is expected that this number will increase dramatically in the near future as the population of the U.S. age. Usually, MSCs are used in confined, and in times very crowded, spaces and as a result accidents are bound to occur.

Motorized Shopping Carts (MSCs) are fundamentally reduced speed scooters with large basket installed in their front and in cases of three wheel scooters two small casters are installed in the front in order to enhanced stability (see Figure $1)$.

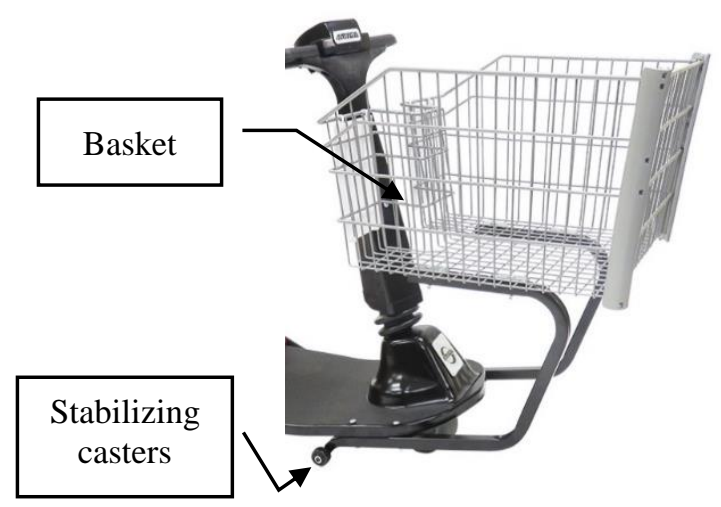

Fig. 1 Modification to a typical scooter.

Digital Object Identifier (DOI):

http://dx.doi.org/10.18687/LACCEI2019.1.1.242

ISBN: 978-0-9993443-6-1 ISSN: 2414-6390
Large number of scooters are currently being used by elderly and people with disabilities and safety issues related to their design and use had been discussed in many reports [2-6]. However, the particular issues regarding the safety of Motorized Shopping Carts had not be discussed In [7] the new rules regarding to mobility aids, published by the American with Disabilities Act, are explained but safety remarks or recommendation were given. In [8] the following hazards were expressed: "A concern over the carts leading to injuries when used by those who do not know how to control them. Injuries can occur to the operator, to other persons and to property if they crash into an object or a person with the equipment. Frontal crashes leading to injuries and property damage are the most common injury. Most units have back-up alarms to warn person(s) when the equipment is in reverse". In [9] other concerns brought forward: 1) "The physical and mental capability of the person operating the device. Capabilities can include: reduced eyesight, diminished capacity due to medication, or alcohol, and limited physical movement (cannot turn around to view when backing up), etc. and 2) "The speed, and the combined weight of the equipment and the operator of the scooter or cart is the best indicator of the severity of the injury or extent of the damage".

The purpose of this paper is to discuss and to some degree quantify some of the hazards related to the use of Motorized Shopping Carts which were mentioned in the above references.

\section{START-STOP ACCELERATION AND JERK}

It is quite clear that MSCs are used in GO - STOP mode as shopper are driving from one location to another and stop to pick up a certain item. All MSCs are using Direct Current motors to propel the cart and magnet brakes to stop it. Direct current characteristic is high torque at law speed that can result in high accelerations. Magnetic brakes are on/off devices and when engaged they might cause high decelerations. Experiments, in which the acceleration and the deceleration of a commercial MSC traveling along a straight path, were performed. In these experiments the basket was empty and the MSC was driven by $156[\mathrm{lb}]$ rider. The recorded acceleration is shown in Figure 1 ( $F$ stands for forward motion, $\mathrm{R}$ for reverse and $\mathrm{S}$ for Stop). The acceleration signal was samples at $100[\mathrm{~Hz}]$ and filtered with a first order low pass filter with time constant of 0.2 second.

As shown in Figure 2 the acceleration in the forward or reverse direction is practically the same and its peak reaches $0.075[\mathrm{~g}]$. On the other hand, when the brakes were applied the deceleration peaks at $0.14[\mathrm{~g}]$. To determine the jerk, the

$17^{\text {th }}$ LACCEI International Multi-Conference for Engineering, Education, and Technology: "Industry, Innovation, And Infrastructure for Sustainable Cities and Communities", 24-26 July 2019, Jamaica. 
acceleration signal was numerically differentiated and then filtered by a first order low pass filter with time constant of 0.2 second (see Figure 3). As shown, stopping while moving in reverse generates jerk in the order of $0.42[\mathrm{~g} / \mathrm{sec}]$ and $0.3[\mathrm{~g} / \mathrm{sec}]$ when accelerating forward.

Similar results were reported in [10] where the following measurement were found: maximum forward acceleration of $0.163[\mathrm{~g}$ ] stopping deceleration of $0.183[\mathrm{~g}$ ] forward jerk of $0.29[\mathrm{~g} / \mathrm{sec}]$ and stopping jerk of $0.345[\mathrm{~g} / \mathrm{sec}]$. In [11] four different scooters were tested on horizontal surface. The measured maximum forward acceleration was found to be $0.194[\mathrm{~g}]$ and in the reverse direction $0.363[\mathrm{~g}]$.

ANSI/ASCE Standard 21.2-08 [4] specifies the maximum acceleration and jerk allowed in public transportation (see Table 1). Comparing to the measurements mentioned above, only one scooter exceeds the allowed acceleration but in two cases the jerk is larger than the allowed values. Although this standard is not directly related to MSCs, it does, however, dictate the limitation on acceleration and jerk so that the rider will be kept in his seat.

TABLE I

MAXIMUM ACCELERATION AND JERK DICTATED BY ANSI/ASCE STANDARD

\begin{tabular}{|l|c|c|}
\hline \multirow{2}{*}{\multicolumn{1}{|c|}{ Direction }} & \multicolumn{2}{c|}{ Acceleration [g] } \\
\cline { 2 - 3 } & Standing & Seating \\
\hline Lateral & \pm 0.1 & \pm 0.25 \\
\hline Vertical & \pm 0.05 & \pm 0.25 \\
\hline Longitudinal Normal & \pm 0.16 & $\pm \mathbf{0 . 3 5}$ \\
\hline Longitudinal Normal* & \pm 0.32 & \pm 0.60 \\
\hline & \multicolumn{2}{|c|}{ Jerk [g/s] } \\
\hline Lateral & \pm 0.06 & \pm 0.25 \\
\hline Vertical & \pm 0.04 & \pm 0.25 \\
\hline Longitudinal & \pm 0.10 & $\pm \mathbf{0 . 2 5}$ \\
\hline
\end{tabular}

*Including effect of grade

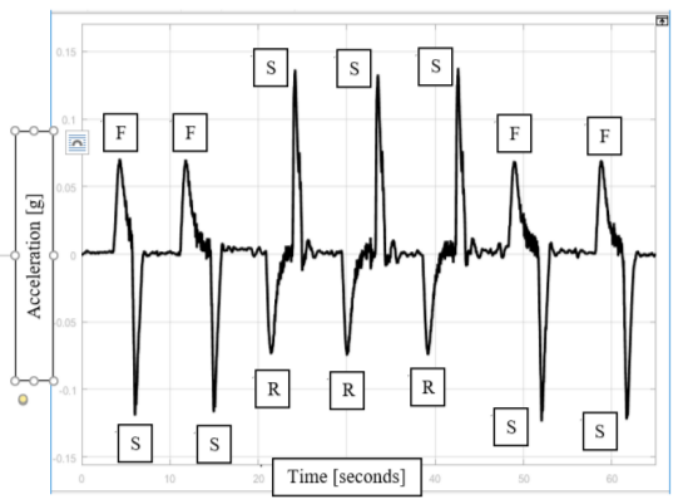

Fig. 2 Acceleration recording

\section{IMPACT WITH A BY STANDING SHOPPER}

MSCs operate in facilities that might be extremely crowded in times such as department stores during the holiday seasons. As a result, collisions with by standers or walking shopper are not avoidable. The following are two simple model by which the impact force can be estimated.
Applying linear momentum principle to the shopping cart:

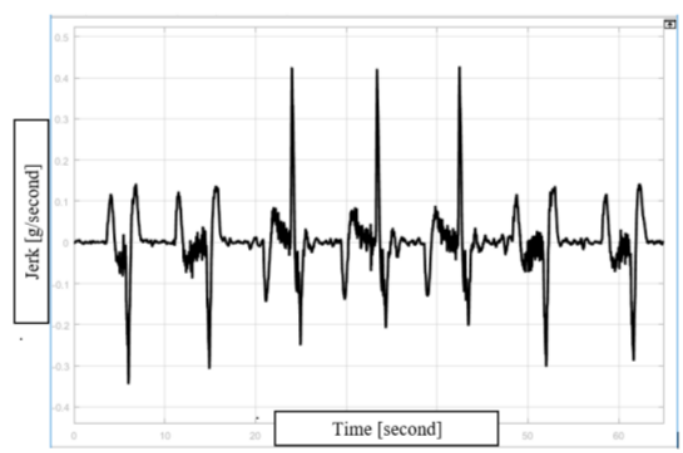

Fig. 3 Calculated jerk

$$
m_{c} v_{1}=\int_{0}^{T} f(t) d t+m_{c} v_{2}
$$

where $m_{c}$ - cart's mass (including the defendant and the basket's contain)

$v_{1}$ - cart's speed before impact

$v_{2}$ - cart's speed after the impact

$f(t)$ - force impulse

$T$ - Impact duration

Since the cart lost speed due to the impact we can rewrite Eq. 1 as:

$$
m_{c}\left(v_{1}-v_{2}\right)=m_{c} v_{1}(1-L)=\int_{0}^{T} f(t) d t+m_{c}
$$

where $L$ is the fraction of the velocity lost during the impact.

For a simple model, in which the impact force $f(t)=F_{0}$ [Lb] and impact duration of $T$ [second], the magnitude of the impact force can be determined by:

$$
F_{0}=\frac{1}{T} m_{c} v_{1}(1-L)=K m_{c} v_{1}
$$

where $K=\frac{1}{T}(1-L)$

Considering the following case: rider weight - 170[1b], Basket weight $=50[\mathrm{lb}]$ and the data for cart A (see Table 2) (cart weight $=190[\mathrm{lb}] v_{l}=3.66[\mathrm{ft} / \mathrm{sec}]$. Figure 4 illustrates the value of $F_{0}$ as function of the impact duration time, $T$, and the fraction of the MSC velocity loss $L$.

A better model for the force impulse is as sine function with half a period $\mathrm{T} / 2[\mathrm{~s}]$ :

$$
f(t)=F_{0} \sin (\omega t)=F_{0} \sin \left(\frac{2 \pi}{T} t\right)
$$

where $F_{0}$ is the maximum value of the force

The total force impulse, $I$, is given by:

$$
I=F_{0} \int_{0}^{T / 2} \sin \left(\frac{2 \pi}{T} t\right) d t=F_{0} \frac{T}{\pi}
$$

Thus the magnitude of the force can be determined

$17^{\text {th }}$ LACCEI International Multi-Conference for Engineering, Education, and Technology: "Industry, Innovation, And Infrastructure for Sustainable Cities and Communities", 24-26 July 2019, Jamaica. 


$$
F_{0}=\frac{\pi}{T} m_{c} v_{1}(1-L)
$$

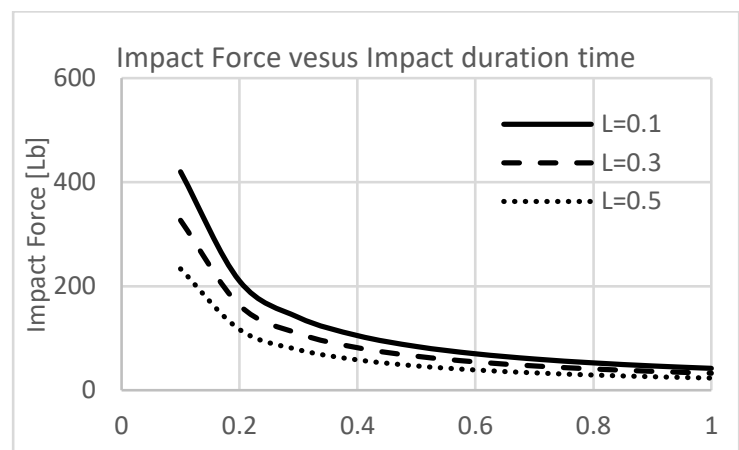

Fig. 4 Impact force as function of impact duration time and cart's velocity lose.

TABLE II

DATA FOR TWO COMMERCIAL MSC'S

\begin{tabular}{|c|c|c|c|}
\hline Property & & $\begin{array}{c}\text { Cart } \\
\text { A }\end{array}$ & $\begin{array}{c}\text { Cart } \\
\text { B } \\
\end{array}$ \\
\hline \multirow[t]{4}{*}{ Weights [Lb] } & Rider & 750 & 500 \\
\hline & Cart & 190 & 167 \\
\hline & Basket & 250 & 250 \\
\hline & Total & 1190 & 917 \\
\hline Cart Dimensions [in] & & $\begin{array}{c}55 \mathrm{~L} \\
26 \mathrm{~W} \\
38 \mathrm{H} \\
\end{array}$ & $\begin{array}{c}56 \mathrm{~L} \\
24 \mathrm{~W} \\
33 \mathrm{H} \\
\end{array}$ \\
\hline Basket dimensions [in] & & $\begin{array}{c}23 \mathrm{~L} \\
25.5 \mathrm{~W} \\
20 \mathrm{H}\end{array}$ & $\begin{array}{c}23.6 \mathrm{~L} \\
19 \mathrm{~W} \\
14.8 \mathrm{H} \\
\end{array}$ \\
\hline \multirow[t]{2}{*}{ Speed [mph] } & Forward & 2.5 & 2.3 \\
\hline & Reverse & 1.5 & 1.4 \\
\hline Wheel diameter [in] & & 8 & $\begin{array}{l}8 \text { - rear } \\
6 \text { - front }\end{array}$ \\
\hline Turning radius [in] & & 34 & 38 \\
\hline Stopping Distance [in] & & & $18 ”$ \\
\hline
\end{tabular}

Equation 5 indicates in this, which is more realistic response, the maximum value of the impact force is $\pi$ time larger. Figure 5 illustrates the impact force as function of time for $F_{0}=300[\mathrm{lb}]$ and MSC's speed used in Figure 3, with impact duration time of 0.25 [sec] and $L=0.25$. The graph indicates that the MSC will exert a force of $250[\mathrm{Lb}]$ for 0.1 [sec] during the impact.

This impact force might be exerted, with high probability, in two body locations: at the torso (impact with the top of the basket) or the ankle (impact with the cart's bumper) as shown in Figure 6. In the first case a person might lose his stability and fall and in the second case a person will injure or even brake his ankle which requires a long heeling time.

To estimate the magnitude of the impact force, exerted by the basket tip, that required to tip over a person, a multibody human model must be used. However, a rough estimate can be obtained by considering the human body as a rigid body.

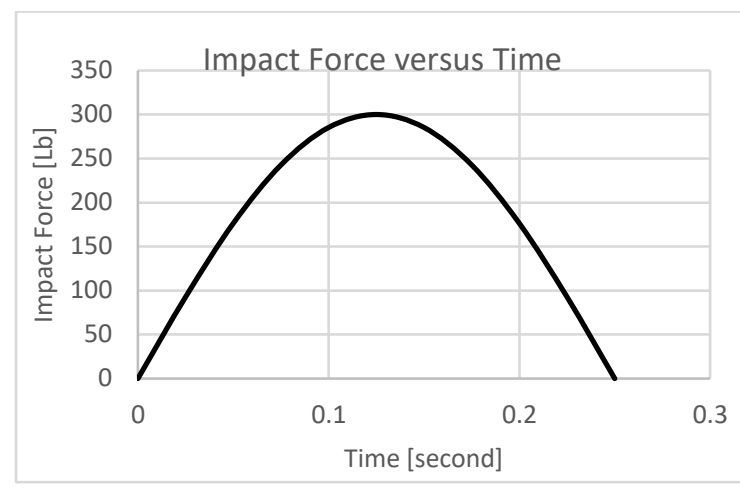

Fig. 5 Impulse shape for a maximum force of $100[\mathrm{lb}]$ and a period of 0.5 [second].

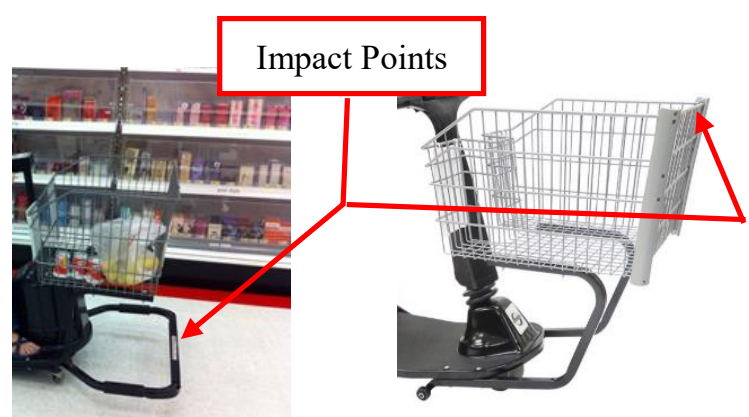

Fig. 6 High probability impact points.

Figure 7 illustrates the Free Body Diagram describing all the forces acting on a person at the tipping instant. The magnitude of the impact force, $F_{0}$, is given by:

$$
F_{0}=\frac{W d}{2 H}
$$

where $H$ is the height of the tip of the basket and $d$ is the span between the feet of standing person.

For $H=33$ [in] (above the center of gravity of the standing person) and $d=12$ [in] Eq. yields $F_{0}=31[l b]$. As shown above the impact force can assume by far larger magnitude which for certain might cause a by stander to lose his balance and fall and possibly be injured.

\section{OTHER ISSUES}

\section{A. Turning radius}

Users of MSCs most probably drove standard family vehicle for many years and got used to their performance. One issue in driving a car is to clear its corner while making a turn in a tight space. With a car the maximum radius of rotation is slightly larger than the radius of rotation of front wheel (left front in the Figure 8), In contrast, the maximum radius of rotation of a typical MSC is by far larger than the radius of rotation of front wheel. This fact presents a major difficulty when a tight turning maneuver is performed such as turning into a narrow isle since the rider has to clear the edge of the basket. In comparison, driving the MSC is like driving a mini excavator where the bucket is extended. Also, one has to realize that most of the MSCs users are probably using scooters for daily

$17^{\text {th }}$ LACCEI International Multi-Conference for Engineering, Education, and Technology: "Industry, Innovation, And Infrastructure for Sustainable Cities and Communities", 24-26 July 2019, Jamaica. 
mobility. These scooters do not have baskets, or very small ones, thus they need some adjustment time to drive a MSC which has a large basket in is front.

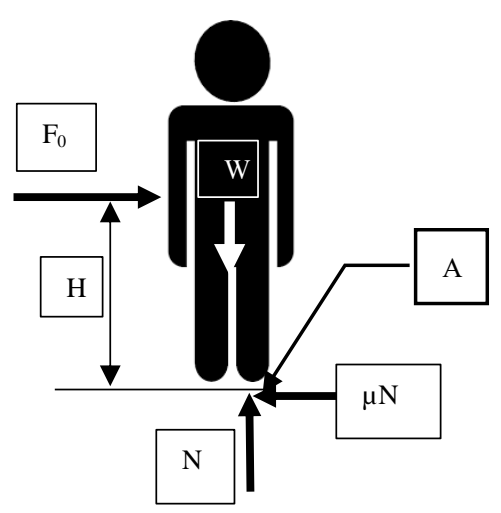

Fig. 7 Free body diagram of a person on a verge of tipping.

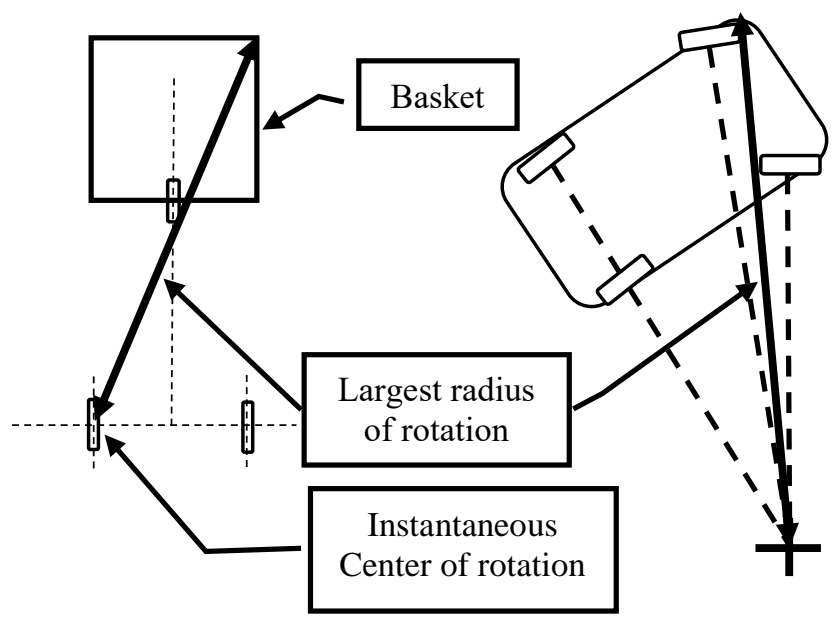

Fig. 8 Turning radii of a car and a MSC.

\section{B. $\quad$ Stopping Distance (SD)}

The stopping distance (SD) provided by the manufacturer of cart B is $1.5[\mathrm{ft}]$ which relates to the capability of the brakes to bring the cart to a halt. This value does not agree with measurements taken in several experiments. One such is shown in Figure 9 where the acceleration signal was integrated twice and the stopping distance was estimated to be about $4[\mathrm{ft}]$ to which the distance the cart travels during the rider's response time. The actual stopping distance should include the distance the cart travels during the response time of the rider. Typical response time is 1.5 [second] and for elderly people it might be higher. Thus for a traveling speed of $2.4[\mathrm{mph}]$, as specified by the manufacturer of cart $\mathrm{B}$, the stopping distance is:

$S D=1.5+1.5 * 2.4 * 1.466=6.78[\mathrm{ft}]$

Thus the actual stopping distance, if the rider pays full attention, is about 7.0[ft]. One has to realize that the attention of the rider is in finding a particular product while driving along an isle. The products are located on shelves on both of his sides and as a result he is not looking forward in the driving direction. In this case stopping distance becomes very critical in particular in crowded store.

In [10] one of the four scooters tested had a stopping distance of $7.578[\mathrm{ft}]$ from a speed of $2.51[\mathrm{ft} / \mathrm{sec}]$. This value is comparable to the calculated in Eq. 8. The stopping measurement recorded in one of the experiments was 4[ft] once the brakes were applied. To this value one has to add the distance covered due to the response time of the driver:

$$
S D=4+1.5 * 2.4 * 1.466=9.28[\mathrm{ft}]
$$

C. Tipping Over

Some three wheel MSCs do not have stabilizing casters and as a result, they are more susceptible to tipping. In this case, the MSC will tip to the right once the center combined center of gravity of the rider, the cart and the basket and its content will cross the tip over line that connects the centers of the right rear and the front wheel (see Figure 9). Tipping can occurs when the rider over extends his arm and shift his weight in order to reach a product or while standing on the platform and shifting his weigh to one foot in order to reach a product on a high shelf.

In this regard the label attached to the MSC warns: 1) "Do not stand on the platform; and 2) "Distribute weight evenly in basket". The only question is: "how many of the users actually reading the label?"

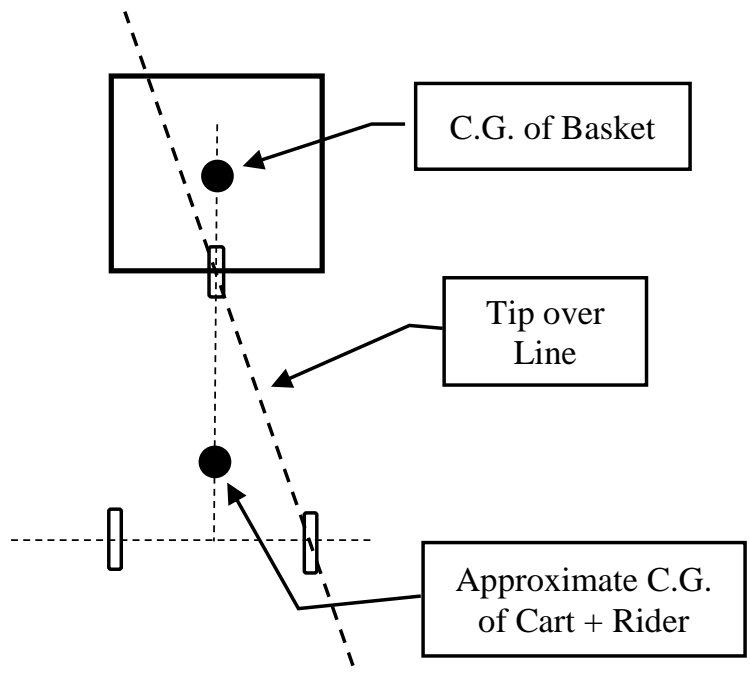

Figure 9: Tipping diagram of an MSC.

\section{CONCLUSIONS}

It is expected that the number of Motorized Shopping Carts will increase considerably in the near future as population age. MSCs do present risk to an inexperienced rider and bystanders in particular in crowded spaces like department store during holiday season. 
Injuries due to impact with by standers, tip over, falling of the cart due to high acceleration and other reasons were presented in this paper. Some changes in the design of these carts, such as soft bumpers and proximity sensors, will reduce the risk, However, the real problem is that the accessibility to these carts is not monitored by the facility's personnel. Therefore anyone, capable or not, experienced or not, can use these carts. Since these facilities do provide these carts to their customers it is their responsibility for their safe usage. A few minutes of one to one instructions will make the user aware of these safety issues and thus reduce the risk.

\section{REFERENCES}

[1] https://www.statista.com/statistics/240892/number-of-ussupermarket-stores-by-format/

[2] Jonine Jancey, et. al., "Pedestrian and Motorized Mobility Scooter Safety of Older People", Traffic Injury Prevention (2013) 14, 647653

[3] Adrian Bingham, Xavier Hadoux, Dinesh Kant Kumar, Implementation of a safety system using ir and ultrasonic devices for mobility scooter obstacle collision avoidance", IEEE Xplore: 21 August 2014.

[4] A collaborative project involving the Australian Competition and Consumer ommission, NRMA Motoring \& Services, CHOICE, EnableNSW and Flinders University,"Mobility scooter usage and safety survey report", September 2012 (https://www.productsafety.gov.au/system/files/Mobility\%20scooter \%20usage\%20and\%20safety\%20survey\%20report.pdf)

[5] AGEING AND TRANSPORT MOBILITY NEEDS AND SAFETY ISSUES: MOBILITY NEEDS AND SAFETy IsSUES, OECD PUBLISHING, OCTOBER 25, 2001.

[6] Erin Cassell, Angela Clapperton, Consumer product-related injury (2): "Injury related to the use of motorised mobility scooters", Hazard (Edition No. 62), Summer - Autumn 2006, Victorian Injury Surveillance, Unit (VISU) www.monash.edu.au/muarc/visu, Monash niversity, Accident Research Centr

[7] Wheelchairs, Mobility Aids, and Other Power-Driven Mobility Devices, U.S. Department of Justice Civil Rights Division Disability Rights Section

[8] ZURICH RISKTOPICS, "Safety of Mobility Scooters and shopping carts", Feb. 2015

[9] ZURICH Retail Newsletter.3rd Qtr. 2015

[10] Andrew John Rentschler, "Analysis of the NASI-RESNA wheelchair standards A comparison study of 5 different electric powered wheelchairs", M.Sc. in Bioengineering thesis, submitted to Carnegie Mellon University, 1995.

[11] Ana E. Souza, Jonathan L. Pearlman, Rosemarie Cooper, Annmarie Kelleher, Benjamin Gebrosky, Rory A. Cooper, "Evaluation of scooters using ANSI/RESNA standards", Journal of Rehabilitation Research \& Development (JRRD), Vol. 50 No 7, 2013, Pages 1017 - 1034

[12] ANSI/ASCE Standard 21.2-08, Automatic People Mover Standards Part 2, Vehicle Propulsion and Braking, 2008.

$17^{\text {th }}$ LACCEI International Multi-Conference for Engineering, Education, and Technology: "Industry, Innovation, And 